\title{
A new bio-based fibre-reinforced polymer obtained from sheep wool short fibres and PLA
}

Miguel Fernando Aldas Carrasco MSC

Researcher, Departamento de Ciencia de Alimentos y Biotecnología, Facultad de Ingeniería Química y Agroindustria, Escuela Politécnica

Nacional, Quito, Ecuador (corresponding author: miguel.aldas@epn.edu.ec) (Orcid:0000-0003-3491-6618)

Nicolas Jérôme Rouault Eng.

Student, École Nationale Supérieure d'Ingénieurs de Caen, Caen, France

\author{
José Miguel Ferri Azor PhD \\ Researcher, Instituto de Tecnología de Materiales, Universitat Politècnica de \\ València, Alcoy, Spain (Orcid:0000-0002-1269-4973) \\ Juan López-Martínez PhD \\ Professor and Researcher, Instituto de Tecnología de Materiales, Universitat \\ Politècnica de València, Alcoy, Spain (Orcid:0000-0001-6904-2282) \\ María Dolores Samper Madrigal PhD \\ Professor and Researcher, Instituto de Tecnología de Materiales, Universitat \\ Politècnica de València, Alcoy, Spain (Orcid:0000-0002-5102-8412)
}

\begin{abstract}
Within the cheese industry is used the milk of a specific species of sheep whose wool is not suitable for the fibre industry. Therefore, this fibre becomes a waste by-product. To take advantage of this waste, the formulation of a fibre-reinforced polymer based on a poly(lactic acid) (PLA) matrix plasticised with maleinised linseed oil (MLO) is proposed. The work began by evaluating the feasibility of four fibre-cleaning processes. Then, to study the composition and processing conditions of the material, a complete factorial design of experiment $2^{2}$, improved with four centre-points, was considered. Afterwards, the mechanical and thermal properties of the formulations were assessed. The results showed that the most suitable washing method was the one similar to the industrial cleaning process. The reprocessing of the material increased its homogeneity due to an improvement in the fibre-matrix interface. The Pareto chart showed that there was no interaction between the wool content and the number of times the material was reprocessed. In general, the addition of sheep wool to a PLA/MLO matrix did not significantly modify the mechanical and thermal properties of the matrix. These results indicate a viable alternative to reduce the wool waste generated in the food industry by means of new bio-based material formulations.
\end{abstract}

\section{Notation}

$f \quad$ poly(lactic acid) (PLA) weight fraction in each fibre-reinforced polymer

$T_{\mathrm{cc}} \quad$ cold crystallisation temperature

$T_{\mathrm{g}} \quad$ glass transition temperature

$T_{\mathrm{m}} \quad$ melting temperature

$X_{\mathrm{c}} \quad$ degree of crystallinity

$\Delta H_{\mathrm{cc}} \quad$ cold crystallisation enthalpy

$\Delta H_{\mathrm{m}} \quad$ melting enthalpy

$\Delta H_{\mathrm{m}}^{0} \quad$ melting enthalpy of purely crystalline PLA (93 J/g)

\section{Introduction}

Wool is an animal-derived fibre essentially composed of proteins and amino acids and constituted by a complex assembly of phases of different compositions. ${ }^{1,2}$ Wool fibre, as well as other fibres, has rather good elastic and medium mechanical properties, but it is better known not only for its ability to regulate moisture and as an insulator of temperature and sound, ${ }^{3-5}$ but also as a sustainable and natural material and an absorber of volatile organic compounds. ${ }^{6,7}$ Indeed, wool has an insulating ability just a little weaker than mineral and glass wool, for example $(0.05$ against $0.04 \mathrm{~W} /(\mathrm{m} \mathrm{K})){ }^{8,9}$ All of these characteristics have caused this natural fibre to be used by humans in textile applications for more than 3000 years. ${ }^{10}$ Nowadays, the world situation is that the wool of one species called 'Merino' has a quasimonopoly on the aforementioned textile applications of sheep wool thanks to its great softness. ${ }^{1,2}$
In contrast, there is a species of sheep that is specifically raised for its milk and for producing cheese. Therefore, the wool derived from this species appears to be a by-product since the wool of this particular species is not the most wanted for the textile industry, which represents the most common use of this raw material. According to the Food and Agriculture Organization of the UN, the world's production of grassy wool was about $1.4 \mathrm{Mt}$ from 2013 to $2017 .^{11}$

Poly(lactic acid) (PLA) is one of the most commonly known biodegradable polymers. ${ }^{12,13}$ This material has a density between 1.21 and $1.43 \mathrm{~g} / \mathrm{cm}^{3},{ }^{14,15}$ a melting point between 150 and $180^{\circ} \mathrm{C}$ and a glass transition temperature reported to be $60^{\circ} \mathrm{C}^{16-18}$ Its price is around US\$2000-5000/t. ${ }^{19}$ The total amount of plastics produced in 2017 was $348 \mathrm{Mt}$, of which $2 \cdot 11 \mathrm{Mt}$ were bioplastics, where PLA represented $10 \cdot 3 \% .^{20,21}$ The lactic acid monomer naturally exists in several organisms, and for the production of PLA the fermentation of starch using bacteria must take place. ${ }^{22}$ Then, the polymer is created essentially using the ring-opening polymerisation method. ${ }^{13,23,24}$ Furthermore, PLA is considered a compostable polymer because it is degraded and disintegrated under special industrial composting conditions, which often occur at $60^{\circ} \mathrm{C}$ in the presence of microorganisms. ${ }^{12,25}$

Thanks to its biocompatibility, PLA has been extensively used in medicine to make implants, for the controlled release of drugs, in 
biodegradable surgical sutures and in biodegradable fixation devices, such as screws, plates and pegs. ${ }^{13,26}$ Currently, the use of PLA in packaging is increasing due to the growing consideration of the environmental impact of plastics. ${ }^{18,27}$ Moreover, it has been used for three-dimensional printing because it can be easily shaped. ${ }^{28,29}$ The advantages of PLA, such as low toxicity, biocompatibility, easy shaping and compostability, have led to a forecast of increasing growth of the PLA market despite the poor mechanical performance, low temperature resistance and high market price of PLA compared with those of other polymers. ${ }^{30}$

In the materials engineering field, fibre-reinforced polymers (FRPs) have been employed, mainly to replace traditional materials in many structural applications. ${ }^{31-33}$ Likewise, to improve PLA properties, such as temperature resistance, fire resistance and mechanical properties, some papers reported the study of the PLA matrix with different fibres. For instance, FRPs based on a PLA matrix reinforced with $\operatorname{flax}^{34,35}$ or sisal $^{36}$ were used to make a $100 \%$ bio-based material. Furthermore, lignin has been also studied as a natural reinforcement for PLA. $^{37}$ Results showed that it was possible to process the blends and to improve some of the properties of virgin PLA. In addition, wool has also been extensively experimented with as a reinforcement through many different kinds of FRPs, using different matrixes, polypropylene, ${ }^{38-44}$ polyester ${ }^{45,46}$ and others. ${ }^{47,48}$ In many of these studies, the results showed that wool fibres were not only used as mechanical reinforcement fibres, but also as a fire retardant, due to their great thermal properties. ${ }^{49,50}$

Similarly, many natural plasticisers have been used to improve PLA properties, as an environmentally friendly alternative to traditional petroleum-based plasticisers. In this context, some natural vegetable oils and epoxidised vegetable oils have been employed at the industrial level. ${ }^{24,51,52}$ Thus, in a previous work, maleinised linseed oil (MLO) was used as a natural plasticiser and compatibiliser for PLA blends, where it was found that the chemical structure of this plasticiser, which contains maleic anhydride groups, allows some reactions with the hydroxyl groups of PLA. Consequently, MLO (at low contents, i.e.
2-6 parts per hundred resin) leads to an improvement in the mechanical properties of PLA blends. ${ }^{24}$ On this basis, it was decided to add MLO to the PLA matrix, to attempt to obtain an FRP with improved mechanical performance.

To sum up, a study to obtain a biocomposite or a bio-fibrereinforced polymer using PLA and wool fibre does not seem to have been conducted yet, as it has not yet been reported in the literature. Consequently, the aim of this work was to study the feasibility of producing an FRP using PLA as the matrix and wool fibre as the reinforcement to generate an alternative value for this by-product of the alimentary industry and to reduce the wool waste generated in the sheep cheese production process. First, the work began to study the cleaning methodology to obtain wool fibres suitable to use as reinforcement material. Then, a complete factorial design (CFD) of experiment $2^{2}$, improved with four centre-points, and two blank samples were considered to assess the influence of the wool composition and the number of times the material was reprocessed on the properties of the FRP. Moreover, a complete characterisation in terms of mechanical, thermal and microstructural properties was conducted in each material obtained in the development of the designed experiment.

\section{Experimental section}

\subsection{Wool fibre preparation}

The first step of the work was to find an efficient way to clean the wool, to sort it and to cut it in order to be able to use it as a reinforcement material in an FRP. The received wool came directly from the shearing of sheep, so it was extremely dirty and not sorted, as shown in Figures 1(a) and 1(b). It was composed not only of wool, but also of plenty of vegetables, faeces, soil and grease called lanolin, which is invisible to the human eye.

The wool was first sorted by hand in order to remove as much dirt as possible, including big aggregates of waste. It was also sorted depending on the different parts of the animal's body it came from in order to get homogeneous fibres, considering the
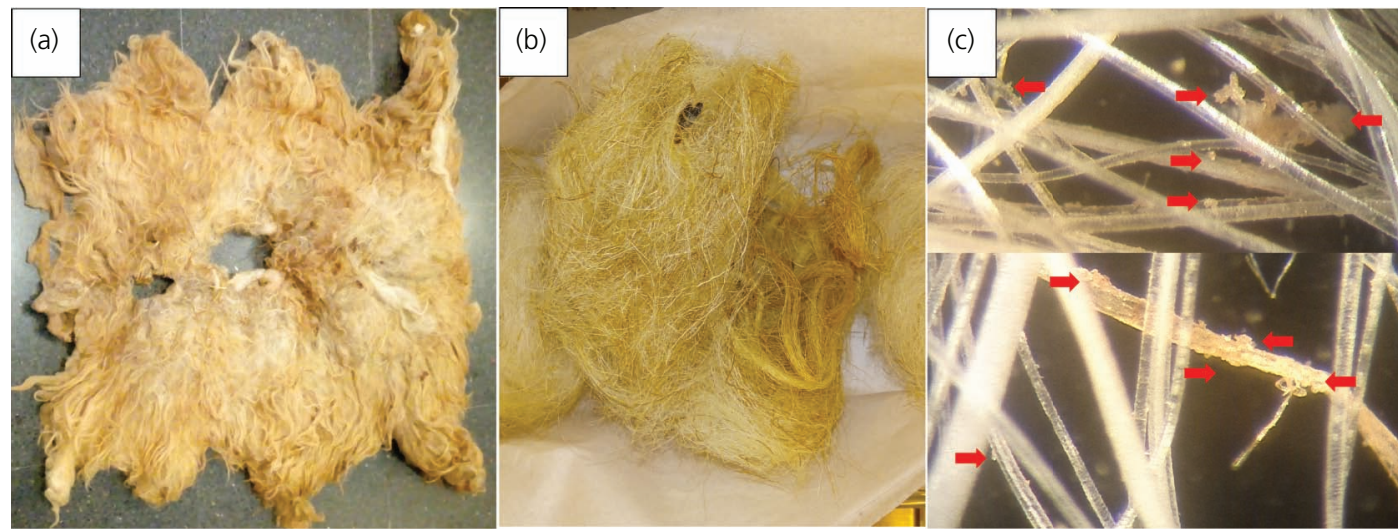

Figure 1. (a) Raw wool fleece; (b) dirty wool as received; (c) optical microscopy image at $\times 56$ zoom of dirty wool fibres 
fact that their properties can differ, according to Charlet et al. ${ }^{53}$ Then, the wool was stretched by hand in order to make the following wash process easier.

Several wool-washing processes were assessed with samples of raw material to find the most efficient one for the aim of this work. The first experiment was conducted with a bath using distilled water at $50^{\circ} \mathrm{C}$, sodium hydroxide $(\mathrm{NaOH})(\mathrm{pH}=12)$ and commercial detergent, based on the washing process performed in the industry, as well as in textile craft. Then, based on the literature and the results obtained in the first bath, it was decided to use sodium carbonate instead of sodium hydroxide as a weaker product. $^{54,55}$

Therefore, four trials of washing processes (A, B, C and D) were studied with different samples of wool in order to find the best methodology for the purpose of this study. The washing processes were performed in a home-type laundry machine as follows

- process A: one water wash (using only water), plus one wash using detergent, plus rinse

- process B: one water wash, plus one wash using detergent, plus one water wash, plus rinse

n process C: one wash using sodium carbonate, plus one water wash, plus one detergent wash, plus one water wash, plus rinse

- process D: one water wash, plus one wash using sodium carbonate and detergent, plus one water wash, plus rinse.

All the washing processes were performed under the following conditions

- $500 \mathrm{ml}$ of distilled water at $50^{\circ} \mathrm{C}$

- sodium carbonate, $\mathrm{pH}=9,1 \mathrm{~g}$ per $500 \mathrm{ml}$

- $10 \mathrm{ml}$ of detergent

- $30 \mathrm{~min}$ of the washing process.

Additionally, the percentage of weight loss after each washing process was measured to quantify the dirtiness removed as an indicator of the performance of the process, since raw wool can contain up to a third of its weight in lanolin, ${ }^{56,57}$ without taking into account the other kinds of impurities, as shown in Figure 1(c) (the red arrows show lanolin and impurities).

Finally, after the cleaning process, the wool fibres were carded to align the fibres to allow the use of wool in an FRP. The carded wool was cut with scissors into $2 \mathrm{~cm}$ length.

\subsection{FRP formulation}

Commercial-grade PLA, Ingeo Biopolymer 6201D, was supplied by NatureWorks LLC (Minnetonka, MN, USA). Its density was $1.24 \mathrm{~g} / \mathrm{cm}^{3}$, and it contained about $1.5 \%$ d-isomer. MLO was supplied by Vandeputte (Mouscron, Belgium). The MLO weight percentage was fixed at $10 \mathrm{wt} . \%$ with respect to the PLA content according to a previous work. ${ }^{24}$ The wool content was established as minimum of $1 \mathrm{wt} . \%$ and maximum of $11 \mathrm{wt} . \%$ fibres in the formulations, based on preliminary processing tests. PLA and wool were dried in an air-circulating oven for $4 \mathrm{~d}$ at $40^{\circ} \mathrm{C}$. Then, each studied formulation was prepared. First, each component of the formulations was mixed in a plastic container.

Next, the prepared formulations were processed in a twin-screw extruder (Dupra SL, Castalla, Spain), with the following temperature profile: $175 / 180 / 180 / 170^{\circ} \mathrm{C}$ (from hopper to die) at 20 revolutions per min. The FRPs were allowed to cool, and then they were milled. Afterwards, the milled material was injected in an injection moulding machine (Sprinter-11, Erinca SL, Barcelona, Spain) to obtain injection moulding test specimens. The temperature profiles for the injection process was set as 170 / $180 / 175^{\circ} \mathrm{C}$ (from hopper to $\mathrm{die}$ ). The test specimens were standard rectangular specimens $(80 \times 10 \times 4 \mathrm{~mm})$ and standard tensile specimens 1BA according to UNE-EN ISO 527-1:2012. ${ }^{58}$ The schematic process followed to obtain and characterise the wool-PLA FRP can be seen in Figure 2.

\subsection{Design of experiment}

As it was noticed that the milling of the FRP had been logically reducing the size of the fibres into the matrix, it was decided to use the number of times that the material was milled and extruded (reprocessed) as a variable of the study. Theoretically, this would allow both reduction of the size of the fibres and improvement of the homogeneity of the blend. Therefore, for studying this variable, some steps for formulating the FRP were repeated as necessary, specifically extruding, cooling and milling. In this work, reprocessing once and three times were studied.

Therefore, the design of experiment chosen in this work was a CFD $2^{2}$, with two factors (wool wt.\% and number of times of reprocessing (extruding/milling)) and two levels - namely, 1 and $11 \mathrm{wt} . \%$ wool content of the material and carrying out reprocessing (the extruding/milling process) once and three times. Thus, four runs were assessed without replication, labelled $1 \% \mathrm{x} 1$, $1 \% \times 3,11 \% \times 1$ and $11 \% \times 3$. The design was improved by adding four centre-point runs to provide information on variability and to make the analysis of variance possible. These points were labelled $6 \% \times 2 \_\mathrm{A}, 6 \% \mathrm{x} 2$ B, $6 \% \mathrm{x} 2 \_\mathrm{C}$ and $6 \% \mathrm{x} 2$ - D. In addition, two trials were conducted with PLA and PLA + MLO formulations, as blank samples, and an additional point (6wt.\% wool and one milling, labelled $6 \% \times 1$ ) was added. In total, 11 blends were processed and characterised. The software employed to analyse the data from the design of experiment was Minitab.

\subsection{Characterisation}

The Shore D hardness of samples with $4 \mathrm{~mm}$ thickness was measured using a model 673-D durometer from Instruments J.Bot SA (Barcelona, Spain), in accordance with ISO 868:2003. ${ }^{59}$ The mean of the measurement of five specimens is reported as the hardness value, as required by the standard. The resistance to Charpy's impact was measured using a Metrotec SA machine (San Sebastian, Spain), using a $6 \mathrm{~J}$ pendulum as per ISO 179- 


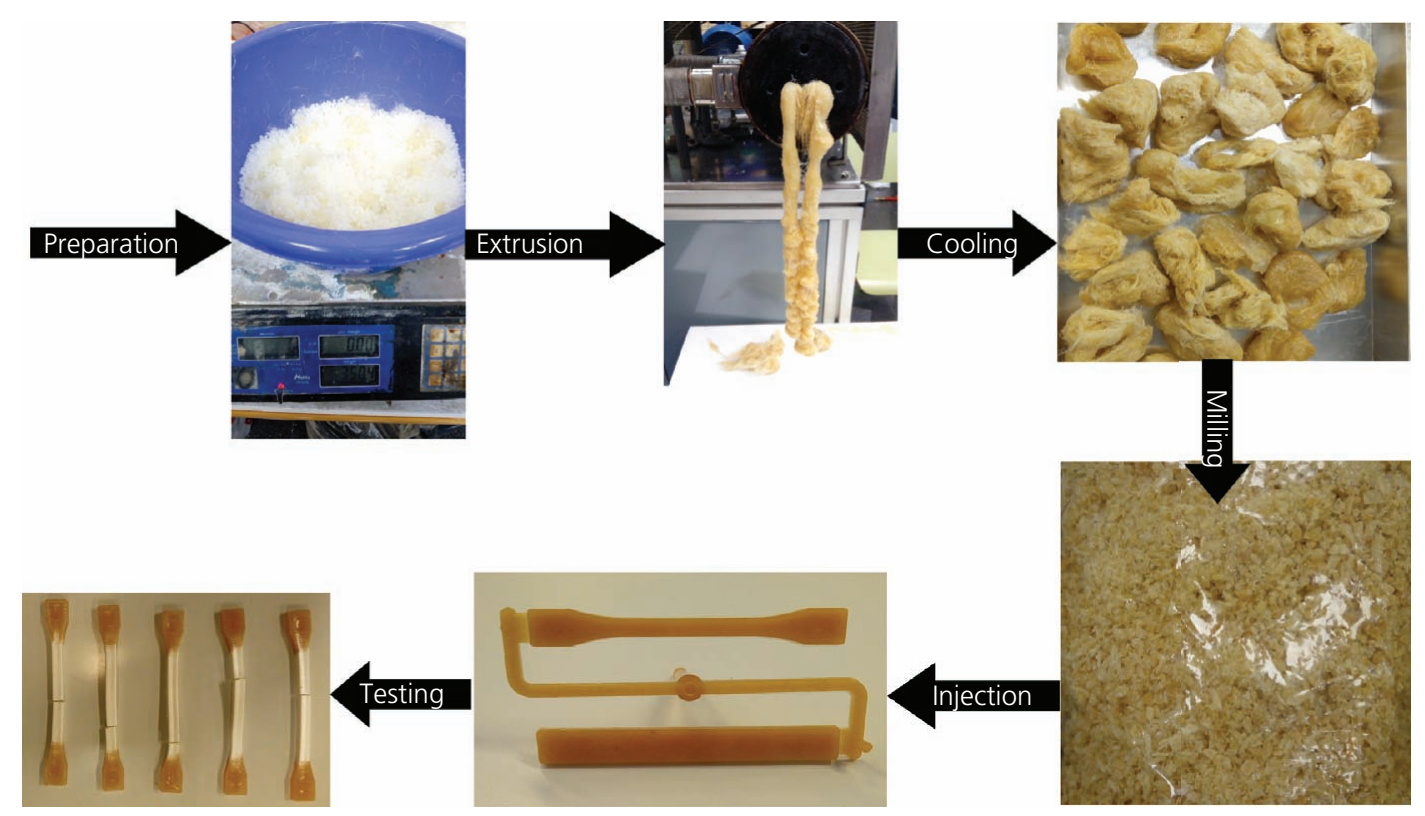

Figure 2. Methodology followed to formulate and assess the FRP of wool-PLA/MLO

$1: 2010 .{ }^{60}$ Following the standard guidelines, ten specimens were tested, and the mean was reported.

The tensile and flexural properties of the FRP were determined using an Ibertest Elib 30 universal testing machine of SAE Ibertest (Madrid, Spain) at room temperature. The tests were performed with a $5 \mathrm{kN}$ loading cell, and the test speed was $10 \mathrm{~mm} / \mathrm{min}$ for tensile tests and $5 \mathrm{~mm} / \mathrm{min}$ for flexural tests, following UNE-EN ISO 527-1:2012 ${ }^{58}$ and ISO 178:2010, ${ }^{61}$ respectively. At least five samples of each formulation were assessed, according to the standards' instructions. The maximum strength, Young's modulus, the elongation at break and the flexural strength are reported.

Differential scanning calorimetry (DSC) assessments were conducted using a DSC 2000 calorimeter from TA Instruments (New Castle, DE, USA) in an aluminium pan, under a nitrogen atmosphere $(50 \mathrm{ml} / \mathrm{min})$, with a ramp from 25 to $250^{\circ} \mathrm{C}$, at a heating speed of $10^{\circ} \mathrm{C} / \mathrm{min}$. The glass transition temperature $\left(T_{\mathrm{g}}\right)$, melting temperature $\left(T_{\mathrm{m}}\right)$, cold crystallisation temperature $\left(T_{\mathrm{cc}}\right)$, cold crystallisation enthalpy $\left(\Delta H_{\mathrm{cc}}\right)$, melting enthalpy $\left(\Delta H_{\mathrm{m}}\right)$ and the degree of crystallinity $\left(X_{\mathrm{c}}\right)$ were determined from the DSC curves.

The degree of crystallinity in percentage $X_{\mathrm{c}}(\%)$ of the formulated wool-PLA FRP was evaluated according to the following equation

1.

$X_{\mathrm{c}}(\%)=\frac{\Delta H_{\mathrm{m}}-\Delta H_{\mathrm{cc}}}{f \times \Delta H_{\mathrm{m}}^{0}} \times 100$ where $\Delta H_{\mathrm{m}}^{0}$ is the melting enthalpy of purely crystalline PLA $(93 \mathrm{~J} / \mathrm{g})$ and $f$ is the PLA weight fraction in each FRP. ${ }^{62}$

Finally, scanning electron microscopy (SEM) of the fracture surface of the impact specimens was carried out using Phenom SEM equipment from FEI (Eindhoven, the Netherlands) with a voltage of $5 \mathrm{kV}$. The samples were fixed to the carrier with double-faced graphite adhesive and subsequently coated with a gold-palladium alloy to allow electrical conductivity, on an Emitech SC7620 sputter coater (Quorum Technologies, East Sussex, UK).

\section{Results}

\subsection{Wool fibre-washing process}

The baths with distilled water $\left(50^{\circ} \mathrm{C}\right)$, sodium hydroxide $(\mathrm{pH}=$ 12) and commercial detergent involved a complete loss of the original physical aspect of the fibres, which means indubitably that the high $\mathrm{pH}$ of the solution was altering the structure of the fibres. Indeed, they were huddled and were compacted in such a way that it was seriously affecting the washing process. Therefore, it was decided to use sodium carbonate as a weaker product instead of sodium hydroxide.

Figure 3 shows the optical microscopy view of the clean fibre after the different washing processes. As observed, the differences between the cleaning methodologies are insignificant. Nevertheless, it is possible to see that the fibres with fewer impurities and less dirtiness on their surface correspond to cleaning method D.

Regarding the percentage of weight loss, calculated as an indicator of the washing process performance, as shown in Figure 4, the highest percentage of dirtiness was removed by processes $A$ and D. In 

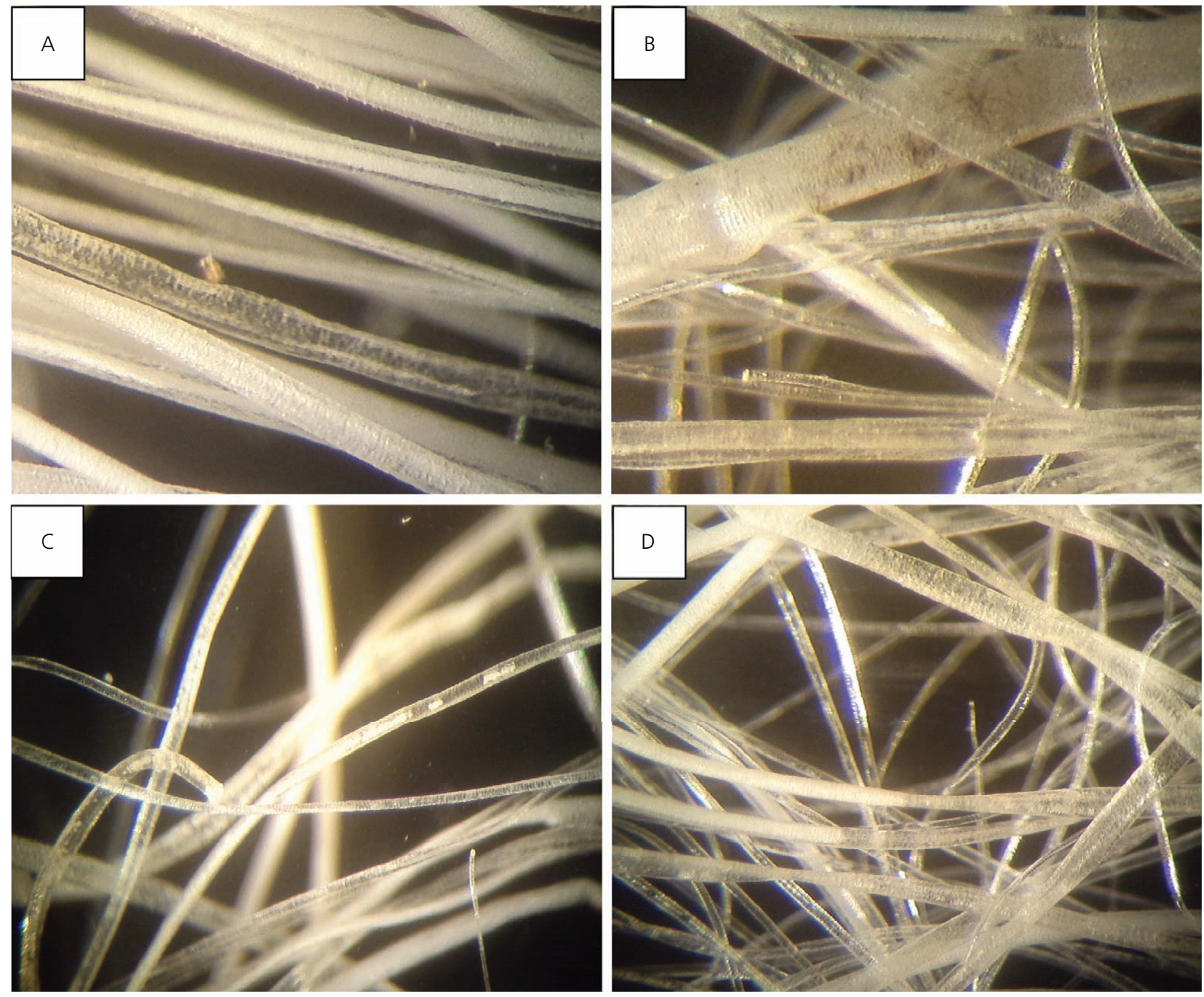

Figure 3. Optical microscopy images at $\times 56$ zoom of fibres from different cleaning processes labelled A, B, C and D

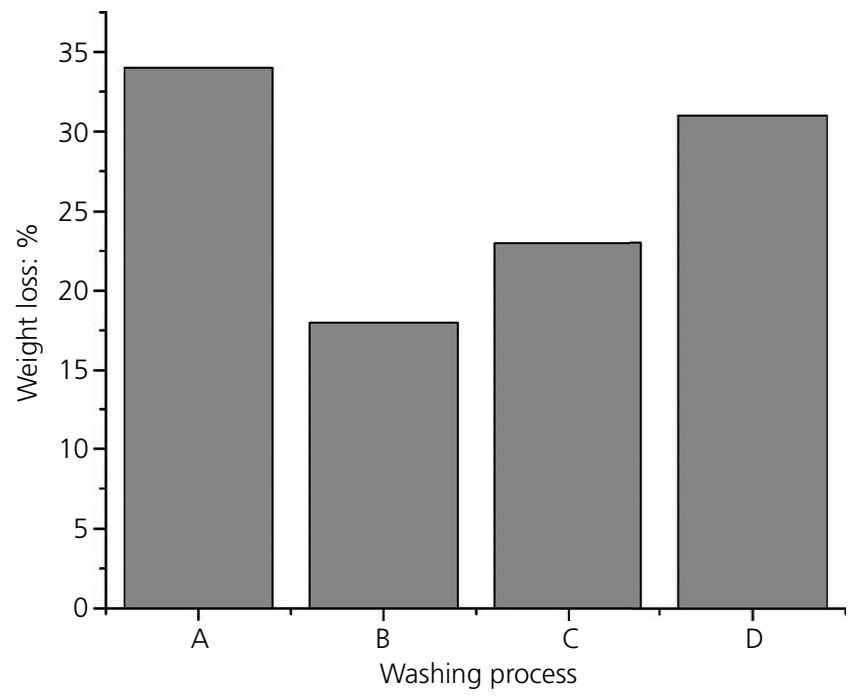

Figure 4. Weight loss of wool fibres after each washing process addition, these cleaning methods required fewer steps than process $\mathrm{C}$, which is not suitable when big volumes of raw wool need to be washed, such as in the present study. Process B removed the least amount of dirtiness among the four methods assessed. Furthermore, since process A was performed in a laundry machine, the wool fibres were very compacted after the cleaning process, which could make the next steps of the study difficult. Therefore, the method chosen to be used in this study, and for large-scale washing, was process D.

Consequently, as a result of the previous washing process experiment and based on the results, to clean $2 \mathrm{~kg}$ of raw wool, the following conditions were established: bath volume: 601 ; water temperature: $50^{\circ} \mathrm{C}$. The wool-cleaning process consisted of the following steps: (a) $20 \mathrm{~h}$ of settling in water in order to take off the main part of soil, dust and dirt; $(b) 5 \mathrm{~h}$ in water with $30 \mathrm{~g}$ of sodium carbonate $(\mathrm{pH}=9)$ and $200 \mathrm{ml}$ of detergent to take the grease off; (c) $14 \mathrm{~h}$ in water as first rinsing to take the foam off; (d) $4 \mathrm{~h}$ in water to eliminate chemical residue; and (e) finally, wringing, dispersing and spreading the wool on a clean $3 \mathrm{~m}^{2}$ surface, to allow drying of fibres, for $3 \mathrm{~d}$. The washing process 

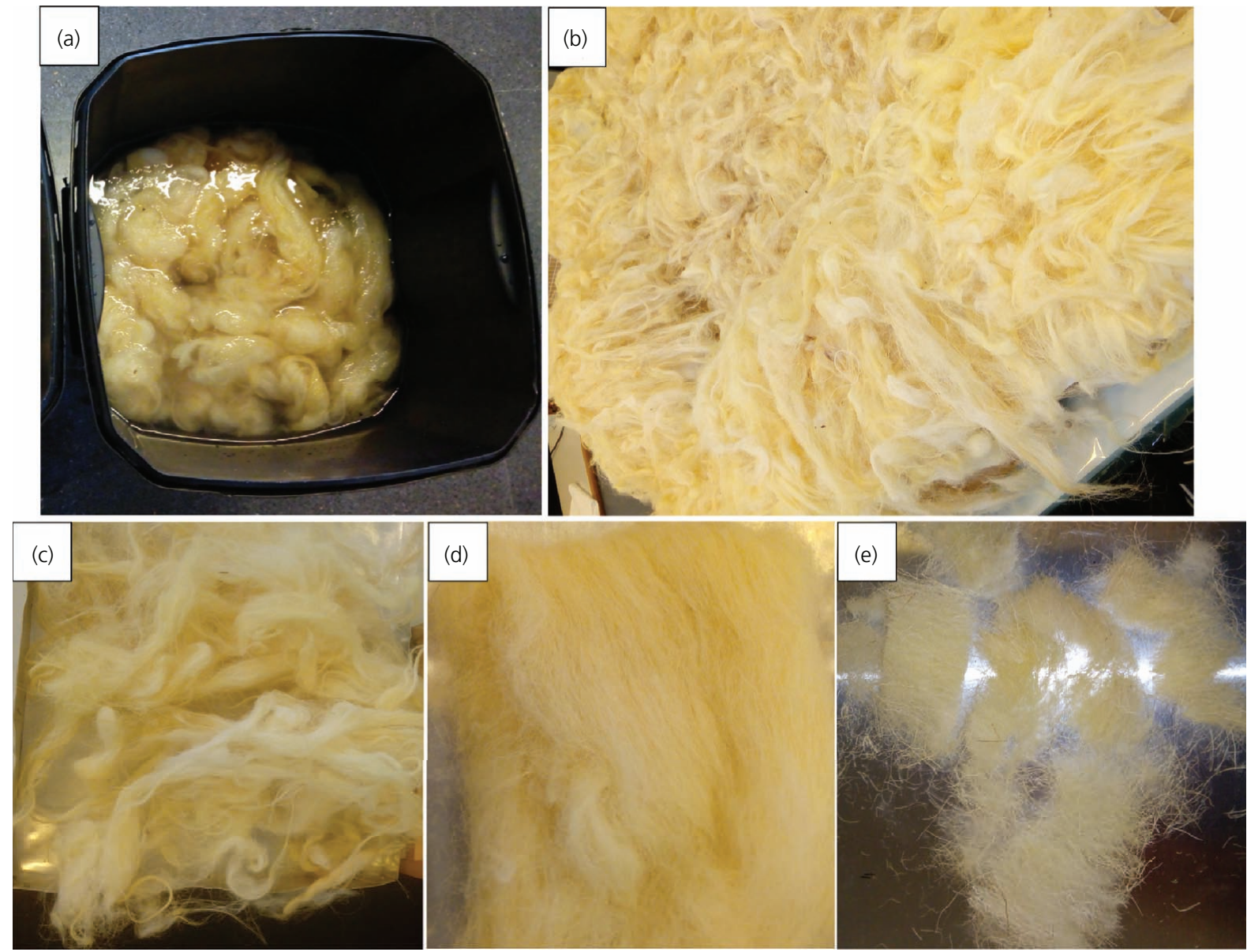

Figure 5. (a) Final wool-washing process; (b) drying process; visual appearances of (c) clean wool, (d) carded wool and (e) $2 \mathrm{~cm}$ cut wool employed in the FRP formulation

was performed in big plastic buckets. Figure 5 shows the results of the final steps of the described process.

\subsection{Characterisation and design of experiment results}

Table 1 shows the results for the different FRP mechanical properties determined in terms of hardness and Charpy's impact, as well as the results of tensile and flexion tests.
Regarding the hardness of the materials, it is possible to observe that the materials containing wool had values similar to those of the control materials (PLA and PLA + MLO). The standard deviation of hardness was not very high, which is indicative of the homogeneity of the material, in terms of this property. In contrast, it can be observed that the incorporation of wool in the biodegradable matrix (PLA and PLA + MLO) decreased the

Table 1. Variation of Shore D hardness, Charpy's impact energy and mechanical and flexural properties of the studied materials

\begin{tabular}{lccccc} 
Formulation & $\begin{array}{c}\text { Hardness } \\
\text { (Shore D) }\end{array}$ & $\begin{array}{c}\text { Charpy's impact } \\
\text { energy: } \mathbf{k J} / \mathbf{m}^{2}\end{array}$ & $\begin{array}{c}\text { Maximum } \\
\text { strength: MPa }\end{array}$ & \multicolumn{1}{c}{$\begin{array}{c}\text { Young's } \\
\text { modulus: MPa }\end{array}$} & $\begin{array}{c}\text { Elongation at } \\
\text { break: \% }\end{array}$ \\
strength: MPa
\end{tabular}


impact resistance. This behaviour can be attributed to the low compatibility of the components in the FRP. It is also noted that in the PLA + MLO material, the impact resistance increased due to the incorporation of MLO, which acted as plasticiser of PLA and therefore allowed greater absorption of energy before the material failed. Finally, it is noted that among the formulated FRPs, the $1 \% \times 3$ material had the greatest reported Charpy's impact resistance, due to the high homogeneity of the material, since it contained fewer fibres and was processed three times.

Concerning the mechanical properties, the reinforcement effect of wool can be confirmed in the formulations containing $1 \%$ fibre $(1 \% \times 1$ and $1 \% \times 3)$. In the values reported in Table 1 , an increase in the elongation at break is verified. This property increased around $500 \%$ with respect to PLA and $42 \%$ with respect to PLA + MLO in the $1 \% \times 1$ formulation. This was because at low concentrations of wool, it was much easier for the fibre to be distributed homogeneously in the matrix and, consequently, the ductility of the material increased.

In contrast, the maximum strength tended to decrease with increment of the wool content. This behaviour was due to the low or null compatibility between the wool and the PLA matrix. It can be remarked that for the case of the maximum strength of the $11 \% \times 3$ material, the decrease in the property reached $50 \%$ compared with that of the base material (PLA + MLO). Regarding the elongation at breakage of the same material, the reduction in properties represents $86 \%$ compared with PLA + MLO and $45 \%$ compared with PLA. Concerning the flexion properties, the maximum property fall occurred likewise in the $11 \% \times 3$ material, with a decrease of $57 \%$ in the flexural strength.

Moreover, if the properties of the materials that were reprocessed $(1 \% \times 3$ and $11 \% \times 3)$ are compared, it can be observed that the more times reprocessing was done, the greater the homogeneity of the material, since the standard deviation of the properties decreased compared with that for the samples processed once $(1 \% \times 1$ and $11 \% \times 1)$. Nevertheless, in any case, the reprocessing of materials resulted in an improvement of the properties.

Finally, referring to Young's modulus, this property decreased in PLA + MLO with respect to that of pure PLA, because MLO acted as a plasticiser. This behaviour is in good accordance with the literature. ${ }^{24,62}$ This draws attention to the observation that the Young's modulus values of materials containing wool are equivalent to each other, regardless of the wool content of the formulation. This performance resulted because when the number of times the material was reprocessed increased, the material tended to be more crystalline, since low-molecular-weight PLA chains were generated by the thermal degradation processes, specifically by the scission process produced by hydrolysis during the processing, generating short chains in the microstructure of the material. ${ }^{12}$ These short chains act as a plasticiser and contributed to a greater crystallinity, and, therefore, the loss of mechanical properties due to the null PLA-wool interaction with the increase of spherulites in PLA, which conferred mechanical resistance to the materials.

With respect to thermal characterisation, Table 2 shows the DSC test values of the formulated materials. If the percentages of crystallinity calculated by the DSC technique $\left(X_{\mathrm{c}}(\%)\right)$ are compared between the PLA + MLO formulation and PLA, it can be observed that the crystallinity of the material increased due to the presence of MLO, as reported in the literature. ${ }^{62}$ In addition, it can be verified that the values of $X_{\mathrm{c}}$ for formulations with the same wool content increased according to the number of times the material was reprocessed. This behaviour confirms what was discussed for Young's modulus - that is, when the number of times the material was reprocessed increases, PLA degrades into smaller chains, which are more easily ordered, and, therefore, $X_{\mathrm{c}}$ increases. ${ }^{12}$ Moreover, if the $X_{\mathrm{c}}$ values of the wool-containing materials are compared with that of PLA + MLO, it can be observed that the crystallisation decreased because the wool fibres prevented the ordering of PLA chains. However, at higher concentrations of wool $(11 \% \times 1$ and $11 \% \times 3)$, the fibres formed agglomerates between them, which generated, on the one hand, large domains of PLA and, on the other hand, domains of fibre. Therefore, the number of crystalline areas in the material increased again because the crystallisation process was not obstructed by the fibres, which allowed a greater number of PLA molecules to be distributed in an orderly manner, and, therefore, a greater number of crystalline zones were generated in the PLA domains.

Regarding $T_{\mathrm{g}}$, it was observed that the value decreased when MLO was incorporated in PLA, due to the plasticising effect that facilitated the mobility of the chains (resulting also in an increase of the crystalline zones $-X_{\mathrm{c}}(\%)$ ). This behaviour is in good accordance with the literature. ${ }^{62}$ Additionally, when wool was incorporated in the formulation, the values of $T_{\mathrm{g}}$ did not have important variations in the materials that contained wool. The decreases detected (which were between 0.5 and $2 \cdot 7^{\circ} \mathrm{C}$, with respect to PLA + MLO) were due to the fact that there was variation in the crystallinity of the materials, previously discussed, and, therefore, the mobility of the chains tended to be greater at low temperatures.

Table 2. Thermal properties of the studied formulations and neat matrix materials

\begin{tabular}{|c|c|c|c|c|c|c|}
\hline Formulation & $\begin{array}{l}T_{\mathrm{g}}: \\
{ }^{\circ} \mathrm{C}\end{array}$ & $\begin{array}{c}T_{\mathrm{cc}}: \\
{ }^{\circ} \mathrm{C}\end{array}$ & $\begin{array}{c}\Delta H_{\mathrm{cc}}: \\
\mathbf{J} / \mathrm{g}\end{array}$ & $\begin{array}{l}T_{\mathrm{m}}: \\
{ }^{\circ} \mathrm{C}\end{array}$ & $\begin{array}{c}\Delta H_{\mathrm{m}}: \\
\mathrm{J} / \mathrm{g}\end{array}$ & $\begin{array}{c}X_{c}: \\
\%\end{array}$ \\
\hline PLA & $61 \cdot 4$ & 99.7 & $22 \cdot 1$ & $171 \cdot 1$ & $46 \cdot 76$ & $26 \cdot 6$ \\
\hline $\mathrm{PLA}+\mathrm{MLO}$ & $60 \cdot 2$ & 88.9 & $6 \cdot 9$ & 172.5 & $32 \cdot 34$ & $30 \cdot 4$ \\
\hline $1 \% \times 1$ & $58 \cdot 2$ & 89.5 & $15 \cdot 4$ & $173 \cdot 6$ & $34 \cdot 38$ & $22 \cdot 9$ \\
\hline $1 \% \times 3$ & $59 \cdot 7$ & $87 \cdot 3$ & $17 \cdot 8$ & $170 \cdot 3$ & $42 \cdot 37$ & $29 \cdot 7$ \\
\hline $6 \% \times 1$ & $59 \cdot 7$ & 88.5 & 18.6 & $170 \cdot 8$ & $37 \cdot 01$ & $23 \cdot 5$ \\
\hline 6\% x2_A & $59 \cdot 1$ & $86 \cdot 7$ & 24.5 & $169 \cdot 6$ & 45.03 & $26 \cdot 1$ \\
\hline $6 \% \times 2 \_B$ & $57 \cdot 5$ & 87.9 & $25 \cdot 2$ & $169 \cdot 2$ & $45 \cdot 83$ & $26 \cdot 3$ \\
\hline $6 \% \times 2 \_c$ & $58 \cdot 7$ & 88.8 & $20 \cdot 6$ & $173 \cdot 1$ & $40 \cdot 73$ & $25 \cdot 6$ \\
\hline $6 \% \times 2$ _D & $59 \cdot 1$ & $86 \cdot 8$ & $20 \cdot 1$ & $172 \cdot 7$ & $40 \cdot 59$ & $26 \cdot 0$ \\
\hline $11 \% \times 1$ & $58 \cdot 0$ & 88.0 & $19 \cdot 4$ & $169 \cdot 7$ & $42 \cdot 68$ & $31 \cdot 2$ \\
\hline $11 \% \times 3$ & $59 \cdot 3$ & $89 \cdot 5$ & $19 \cdot 6$ & $173 \cdot 4$ & $43 \cdot 91$ & $32 \cdot 6$ \\
\hline
\end{tabular}


Additionally, $T_{\mathrm{cc}}$ remained constant and equal to that of PLA + MLO for most of the FRP formulations. The small variations in this parameter can be attributed to the homogeneity of the final material. About the cold crystallisation enthalpy $\left(\Delta H_{\mathrm{cc}}\right)$ and the melting temperature $\left(T_{\mathrm{m}}\right)$, no definite trend was detected. In contrast, the value of the melting enthalpy $\left(\Delta H_{\mathrm{m}}\right)$ increased with the content of wool, in all the formulations, compared with that of the base matrix material PLA + MLO.
On the matter of the microstructure of the studied materials, the SEM images shown in Figure 6 allowed the examination of the fibre-matrix interface in the FRP. First, the characteristic flaky fracture surface of PLA is easily remarkable in Figures 6(a) and $6(\mathrm{~b})$, demonstrating its brittleness. The filaments visible in the image at the greatest zoom (Figure 6(b)) are proof that PLA sometimes presents a plastic behaviour. Moreover, the PLA + MLO surface has a lumpy aspect due to the plasticising effect of
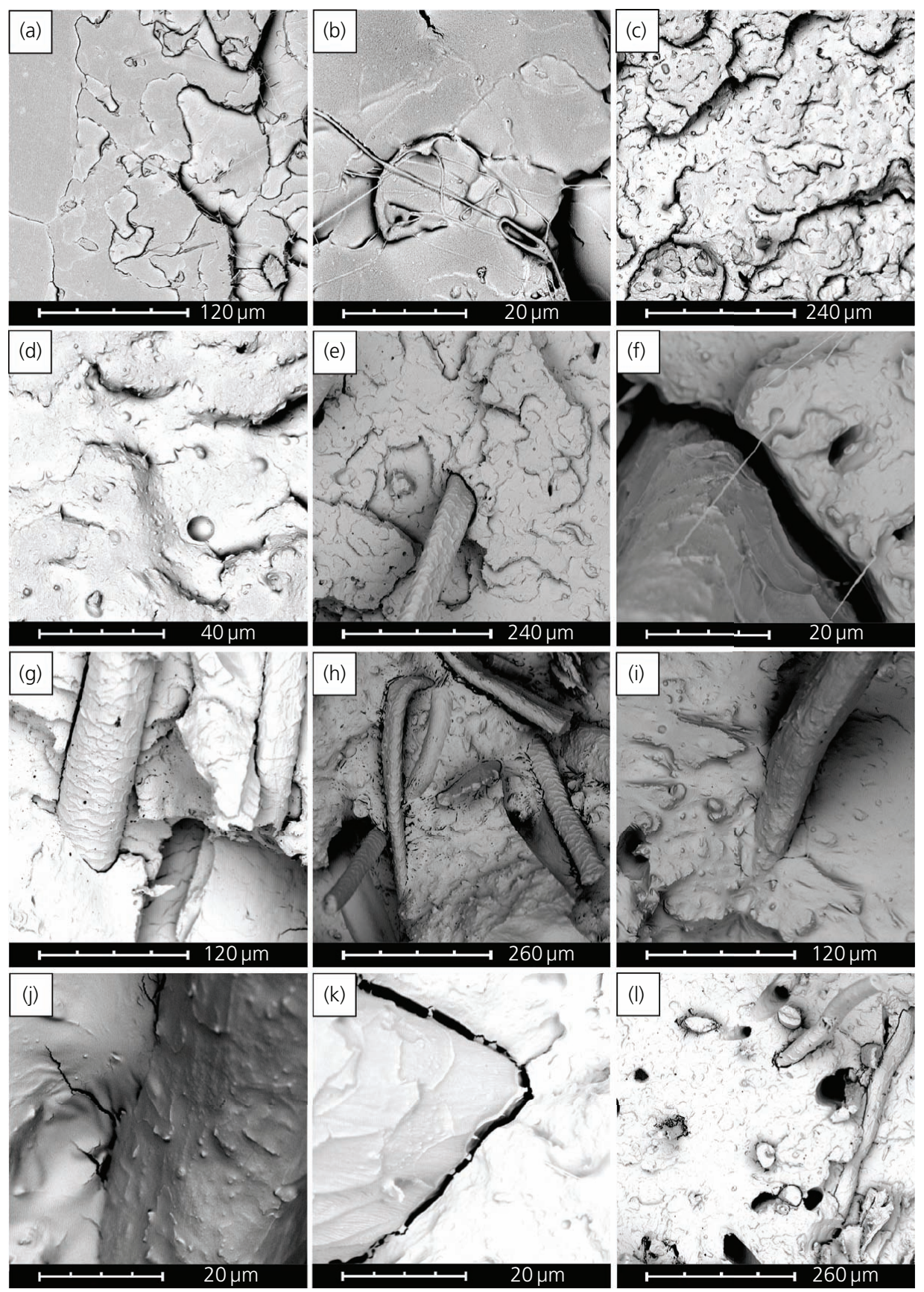

Figure 6. SEM images of fracture surfaces of $(a, b)$ pure PLA, (c, d) PLA + MLO, (e, f) 1\%x1, (g) 6\%x1, (h) 11\%x1, (i, j) 1\%x3, (k) 6\%x2 and (I) $11 \% \times 3$ 
MLO, and the bubbles shown in Figures 6(c) and 6(d) are due to an excess of MLO.

In Figures 6(e)-6(h), corresponding to 1, 6 and $11 \mathrm{wt} . \%$ wool FRP processed once, it is possible to see some wool filaments soaked in the PLA + MLO matrix (Figure 6(e)) and the linking between the wool fibres and the PLA + MLO matrix. Also, the characteristic wool fibre surface, made of solidified cells overlapping each other, is verified. It is possible to establish a very weak structural interaction between the reinforcement and the matrix. At a bigger zoom (Figure 6(f)), it is possible to see poor adhesion between the components of the FRP, which explains the poor mechanical properties. Moreover, Figure $6(\mathrm{~g})$ confirms how easily the fibre was detached from the matrix. As also shown in Figure 6(h), at a high wool content (formulation $11 \% \mathrm{x} 1)$, it is possible to detect that the fibres were distributed in a random way and that there were weak interactions between the components of the material.

However, regarding the reprocessed materials $(1 \% \times 3,6 \% \mathrm{x} 2$ and $11 \%$ $\mathrm{x} 3$ ) shown in Figures 6(i)-6(1), the slight improvement in the fibre-matrix interface is remarkable. It is possible to see that the matrix stuck to the fibres more than the case where only one milling and extrusion process was carried out (Figures 6(i) and 6(j)). Despite this behaviour, the mechanical properties did not improve in the reprocessed formulations, as discussed before. With the highest amount of wool (11\%x1 and $11 \% \mathrm{x} 3)$, the fibres overlapped each other, producing a non-homogenous material, which caused the decrease in the interactions between the fibres and matrix, as shown in Figures 6(h)-6(l). As discussed, in all cases, the values of mechanical properties were lower than those of the matrixes (PLA and PLA + MLO), except for the elongation at the break, where the
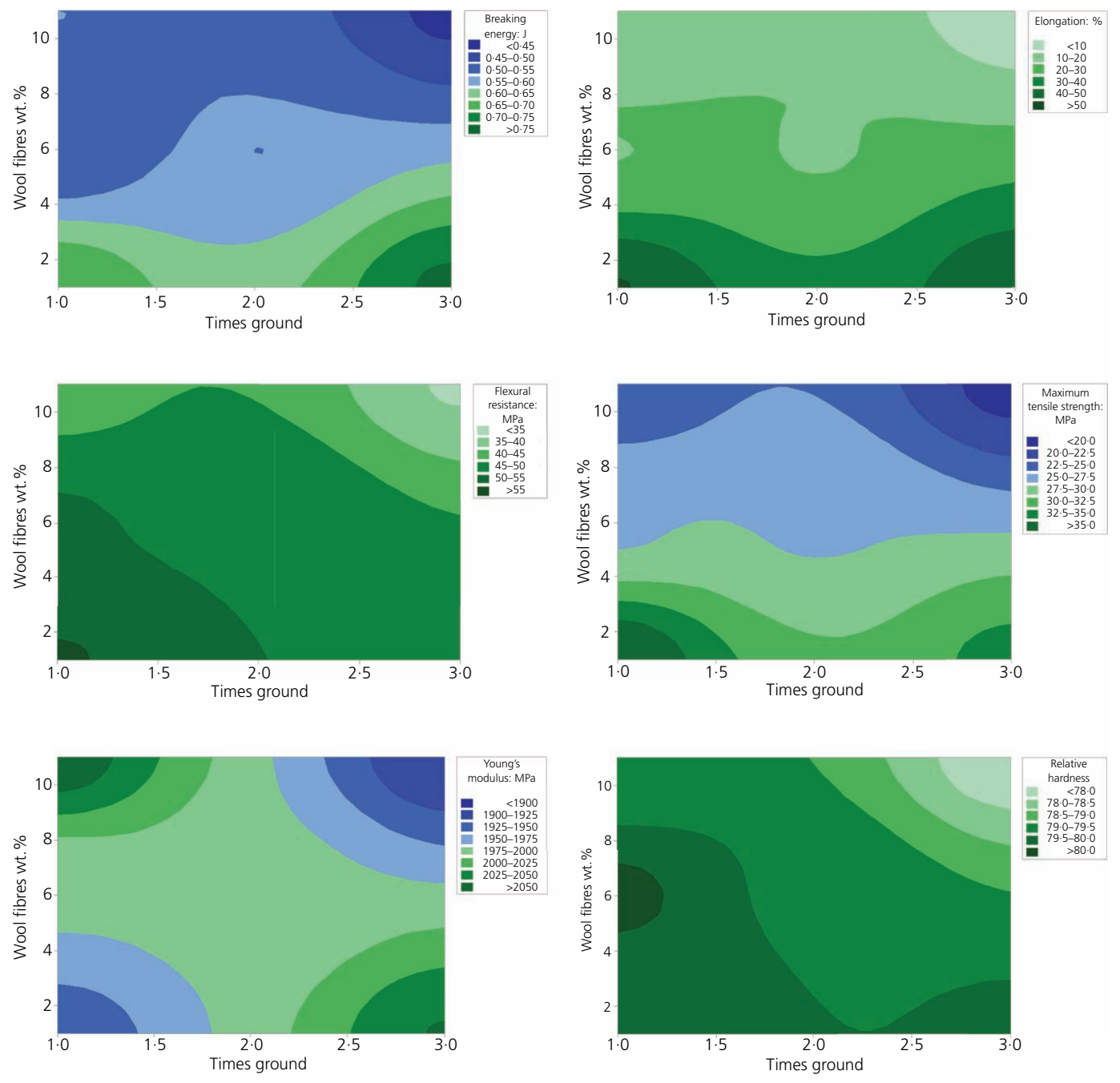

Figure 7. Contour plots obtained from the analysis of the design of experiment 
incorporation of 1 wt.\% wool led PLA and PLA + MLO to gain up to 42 and $15 \%$ more elongation, respectively.

The SEM results revealed the lack of chemical and physical interactions between the wool and the PLA matrix since no good contact at the fibre-polymer interface was observed. This behaviour denotes the importance of a future study to find a coupling agent that could lead to a high reinforcement effect between the wool and PLA, since the properties of the FRPs and composite materials are intimately related to the fibre-matrix interface. For this reason, the chemical modification of the wool fibre surface could be a decisive factor in improving the general properties of the FRP formulations. In the literature reviewed, no information was found about FRPs or composite materials based on PLA and wool. However, in some works that used polypropylene and wool, maleic anhydride was used as a compatibiliser for both materials. ${ }^{38,39}$ In another work, the surface of wool was modified by an oxidation process followed by functionalisation with a silane-based coupling agent, to improve the interaction with polypropylene. ${ }^{63}$ Furthermore, chemical modification of wool can also be done by improving its alkali resistance by removing the covalent bonds of lipids and fatty acids present on the wool surface. ${ }^{47}$ Finally, trisodium citrate, used as a reducing agent for obtaining silver nanoparticles, acts as a linker between wool and silver nanoparticles. ${ }^{64}$

From the contour plots of the experimental results shown in Figure 7, it can be seen that the mechanical properties weakened with the incorporation of wool fibres. Indeed, the contour plots show that the best mechanical properties were obtained with the lowest percentage of wool fibres. Also, it is possible to notice that the reprocessing of the FRP tended to improve the properties of the final material, but it is not mandatory for improving the properties.

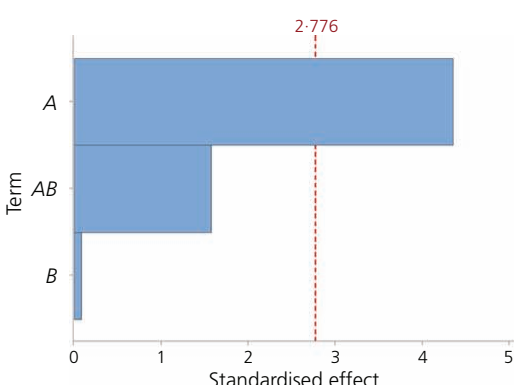

(a)

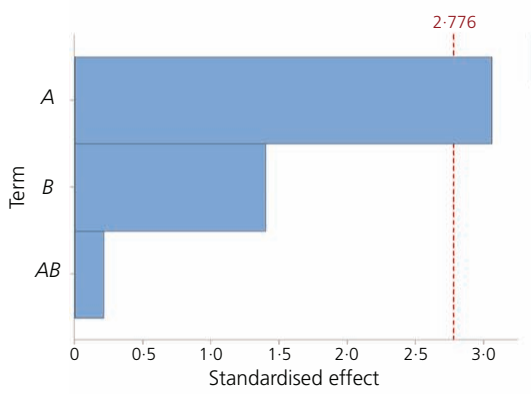

(c)

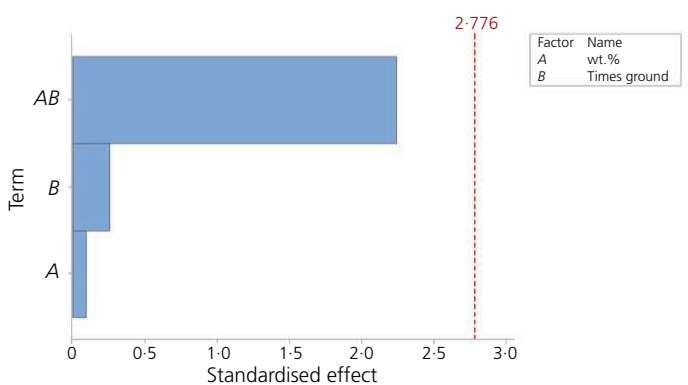

(e)
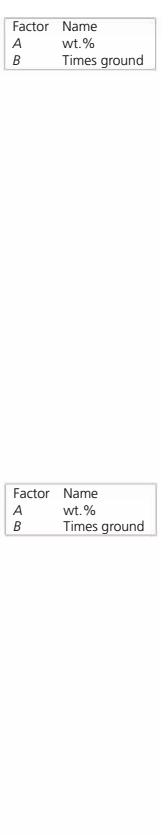

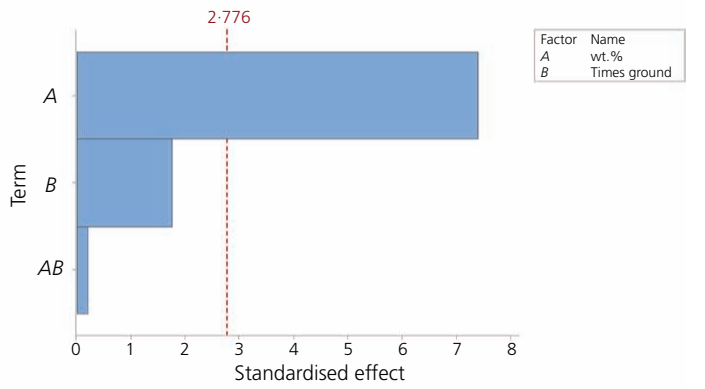

(d)

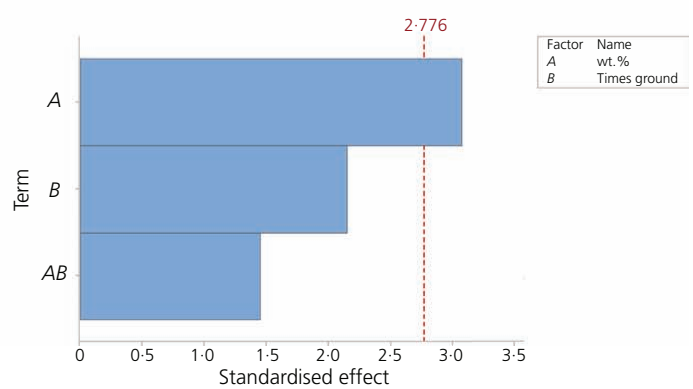

(f)

Figure 8. Pareto charts from the analysis of the design of experiment: (a) breaking energy (J); (b) elongation (\%); (c) flexural resistance $(\mathrm{MPa})$; (d) maximum tensile strength (MPa); (e) Young's modulus (MPa); (f) relative hardness. In all charts $\alpha=0.05$ 
Finally, the Pareto charts shown in Figure 8 confirm that an interaction between the two parameters (wool wt.\% and times of reprocessing) does not exist. Also, the influence of the number of times the material was reprocessed (milled and extruded) is always negligible but contributes positively to the homogeneity of the material based on the standard deviations of the properties. Consequently, the parameter that impacts the properties of the FRP is the wool content.

\section{Conclusion}

In this work, a by-product of the sheep milk and cheese industry was employed in order to formulate a $100 \%$ bio-based and $100 \%$ compostable material. Several technical fields were involved: concepts from the textile industry for obtaining suitable fibres, concepts from the plastics industry for processing the FRP, statistics for the embellishment of the design of the experiment and its analysis and materials science for the characterisation and evaluation of the final products. It was shown that it is possible to produce an FRP based on PLA, plasticised with MLO, as the matrix and wool fibre. The most appropriate washing process for obtaining wool fibres suitable to be employed in the FRP formulation was a first wash with water, a second wash with sodium carbonate and detergent followed by two water washing processes as a rinsing step. Regarding the mechanical properties, the hardness of the formulated materials remains similar to that of the matrix alone, while the Charpy's impact energy decreased with the increment of wool in the FRP. Similar results were obtained for Young's modulus and maximum strength in the tensile and flexural assessments. In contrast, the elongation at break increased with the incorporation of $1 \mathrm{wt} . \%$ wool. Concerning the thermal properties, there was no clearly defined trend and the values present a random behaviour with the increment of wool content in the FRP. Finally, it can be concluded that the reprocessing of the material did not contribute to the improvement of the properties, but it increased the homogeneity of the final material. In general, the use of wool as reinforcement did not significantly modify the mechanical and thermal properties of PLA, although, at low wool concentrations, a slight improvement in the ductile properties was observed. These results open a real possibility to reuse, recycle and take advantage of the wool considered as a waste by-product of the food industry, avoiding waste generation by disposing of these fibres to landfills. This study is a base for future works aimed at improving the properties of formulated materials with superficial modification treatments of wool fibres with coupling agents. With this, an improvement of the fibre-matrix interface could be expected.

\section{Acknowledgement}

This work was supported by the Spanish Ministry of Economy and Competitiveness, Promadepcol (MAT2017-84909-C2-2-R).

\section{REFERENCES}

1. Salpin F (2008) Laine et Colorants: Fixation, Quantification et Vieillissement. Etude par Spectrométrie Raman. Doctoral thesis, Université Pierre et Marie Curie, Paris, France (in French).

2. Hearle JWS (2000) A critical review of the structural mechanics of wool and hair fibres. International Journal of Biological Macromolecules 27(2): 123-138.
3. del Rey R, Uris A, Alba J and Candelas P (2017) Characterization of sheep wool as a sustainable material for acoustic applications. Materials (Basel) 10(11): article 1277.

4. Mirski R, Dziurka D and Trociński A (2018) Insulation properties of boards made from long hemp (Cannabis sativa L.) fibers. BioResources 13(3): 6591-6599.

5. Morris A and Spilsbury K (2016) Commercialisation of a natural material - wool: a bio-based PCM. Green Materials 4(2): 89-97, https://doi.org/10.1680/jgrma.16.00001.

6. Mansour E, Curling S, Stéphan A and Ormondroyd G (2016) Absorption of volatile organic compounds by different wool types. Green Materials 4(1): 1-7, https://doi.org/10.1680/jgrma.15.00031.

7. da Silva CFFP, Rana C, Maskell D et al. (2016) Influence of ecomaterials on indoor air quality. Green Materials 4(2): 72-80, https:// doi.org/10.1680/jgrma.16.00002.

8. Papadopoulos AM (2005) State of the art in thermal insulation materials and aims for future developments. Energy and Buildings 37(1): 77-86.

9. Zach J, Korjenic A, Petránek V, Hroudová J and Bednar T (2012) Performance evaluation and research of alternative thermal insulations based on sheep wool. Energy and Buildings 49: 246-253.

10. Phillips CR and Phillips WD (1997) Spain's Golden Fleece: Wool Production and the Wool Trade from the Middle Ages to the Nineteenth Century. Johns Hopkins University Press, Baltimore, MD, USA.

11. FAO (Food and Agriculture Organization of the UN) (2019) FAOSTAT - Livestock Primary. FAO, Rome, Italy. See http://www. fao.org/faostat/en/\#data/QL/visualize (accessed 17/01/2019).

12. Castro-Aguirre $E$, Iñiguez-Franco $F$, Samsudin $H$, Fang $X$ and Auras $R$ (2016) Poly(lactic acid) - mass production, processing, industrial applications, and end of life. Advanced Drug Delivery Reviews 107: 333-366.

13. Dubey SP, Thakur VK, Krishnaswamy S et al. (2017) Progress in environmental-friendly polymer nanocomposite material from PLA: synthesis, processing and applications. Vacuum 146: 655-663.

14. Daver F, Lee KPM, Brandt M and Shanks R (2018) Cork-PLA composite filaments for fused deposition modelling. Composites Science and Technology 168: 230-237.

15. Jamshidian $M$, Tehrany EA, Imran $M$, Jacquot $M$ and Desobry $S$ (2010) Poly-lactic acid: production, applications, nanocomposites, and release studies. Comprehensive Reviews in Food Science and Food Safety 9(5): 552-571.

16. Yang W, Dong Q, Liu S et al. (2012) Recycling and disposal methods for polyurethane foam wastes. Procedia Environmental Sciences 16: $167-175$.

17. Makwana VA, Lizundia E, Larrañaga A, Vilas JL and Shaver MP (2018) Thermal, optical and structural properties of blocks and blends of PLA and P2HEB. Green Materials 6(3): 85-96, https://doi.org/10. 1680/jgrma.18.00006.

18. Arrieta MP, López J, Hernández A and Rayón E (2014) Ternary PLA-PHB-limonene blends intended for biodegradable food packaging applications. European Polymer Journal 50: 255-270.

19. Södergård A and Stolt M (2002) Properties of lactic acid based polymers and their correlation with composition. Progress in Polymer Science 27(6): 1123-1163.

20. PlasticsEurope (2018) Plastics - the Facts 2018: an Analysis of European Plastics Production, Demand and Waste Data. PlasticsEurope, Brussels, Belgium.

21. European Bioplastics (2018) Bioplastics - Facts and Figures. European Bioplastics, Berlin, Germany.

22. Flieger M, Kantorová M, Prell A, Řezanka T and Votruba J (2003) Biodegradable plastics from renewable sources. Folia Microbiologica 48(1): $27-44$.

23. Piergiovanni $L$ and Limbo S (2016) Plastic packaging materials. In Food Packaging Materials. Springer, Cham, Switzerland, pp. 33-49. 
24. Ferri JM, Garcia-Garcia D, Sánchez-Nacher L, Fenollar O and Balart R (2016) The effect of maleinized linseed oil (MLO) on mechanical performance of poly(lactic acid)-thermoplastic starch (PLA-TPS) blends. Carbohydrate Polymers 147: 60-68.

25. Arrieta MP, Samper MD, Aldas M and López J (2017) On the use of PLA-PHB blends for sustainable food packaging applications. Materials 10(9): article 1108 .

26. Bastioli C (2014) Handbook of Biodegradable Polymers. Smithers Rapra, Shrewsbury, UK

27. Moustafa H, El Kissi N, Abou-Kandil Al, Abdel-Aziz MS and Dufresne A (2017) PLA/PBAT bionanocomposites with antimicrobial natural rosin for green packaging. ACS Applied Materials \& Interfaces 9(23): 20132-20141.

28. Wang X, Jiang M, Zhou Z, Gou J and Hui D (2017) 3D printing of polymer matrix composites: a review and prospective. Composites Part B: Engineering 110: 442-458.

29. Bose S, Vahabzadeh S and Bandyopadhyay A (2013) Bone tissue engineering using 3D printing. Materials Today 16(12): 496-504

30. Plastics Insight (2019) Polylactic Acid Properties, Production, Price, Market and Uses. Plastics Insight, Noida, India. See https://www. plasticsinsight.com/resin-intelligence/resin-prices/polylactic-acid/ (accessed 17/01/2019).

31. Bell B (2009) Fibre-reinforced polymer in railway civil engineering. Proceedings of the Institution of Civil Engineers - Engineering and Computational Mechanics 162(3): 119-126, https://doi.org/10.1680/ eacm.2009.162.3.119.

32. Gengnagel C, Hernández EL and Bäumer R (2013) Natural-fibrereinforced plastics in actively bent structures. Proceedings of the Institution of Civil Engineers - Construction Materials 166(6): 365-377, https://doi.org/10.1680/coma.12.00026.

33. Ren Y, Gavenonis J, Ai R et al. (2013) Glass fiber-reinforced, biobased poly(trimethylene terephthalate) for extrusion. Green Materials 1(4): 218-224, https://doi.org/10.1680/gmat.13.00002.

34. Couture A, Lebrun G and Laperrière L (2016) Mechanical properties of polylactic acid (PLA) composites reinforced with unidirectional flax and flax-paper layers. Composite Structures 154: 286-295.

35. Adomavičiūtè E, Baltušnikaitè J, Jonaitienè V and Stanys S (2015) Formation and properties of textile biocomposites with PLA matrix reinforced with flax and flax/PLA weft knitted fabrics. Fibres \& Textiles in Eastern Europe 23(3): 45-50.

36. Gil-Castell O, Badia JD, Kittikorn T et al. (2016) Impact of hydrothermal ageing on the thermal stability, morphology and viscoelastic performance of PLA/sisal biocomposites. Polymer Degradation and Stability 132: 87-96.

37. Spiridon I and Tanase CE (2018) Design, characterization and preliminary biological evaluation of new lignin-PLA biocomposites. International Journal of Biological Macromolecules 114: 855-863.

38. Conzatti L, Giunco F, Stagnaro P et al. (2013) Composites based on polypropylene and short wool fibres. Composites Part A: Applied Science and Manufacturing 47: 165-171.

39. Kim NK, Lin RJT and Bhattacharyya D (2014) Extruded short wool fibre composites: mechanical and fire retardant properties. Composites Part B: Engineering 67: 472-480.

40. Kim NK and Bhattacharyya D (2016) Development of fire resistant wool polymer composites: mechanical performance and fire simulation with design perspectives. Materials \& Design 106 $391-403$.

41. Kim NK, Bhattacharyya D and Lin R (2013) Multi-functional properties of wool fibre composites. Advanced Materials Research 747: 8-11.

42. Govindaraju R, Jagannathan S, Chinnasamy M and Kandhavadivu P (2014) Optimization of process parameters for fabrication of wool fiber-reinforced polypropylene composites with respect to mechanical properties. Journal of Engineered Fibers and Fabrics 9(3): $126-133$
43. Kim NK, Lin RJT and Bhattacharyya D (2015) Effects of wool fibres, ammonium polyphosphate and polymer viscosity on the flammability and mechanical performance of PP/wool composites. Polymer Degradation and Stability 119: 167-177.

44. Subasinghe A, Somashekar AA and Bhattacharyya D (2018) Effects of wool fibre and other additives on the flammability and mechanical performance of polypropylene/kenaf composites. Composites Part B: Engineering 136: 168-176.

45. Blicblau AS, Coutts RSP and Sims A (1997) Novel composites utilizing raw wool and polyester resin. Journal of Materials Science Letters 16(17): 1417-1419.

46. Conzatti L, Giunco F, Stagnaro P et al. (2012) Polyester-based biocomposites containing wool fibres. Composites Part A: Applied Science and Manufacturing 43(7): 1113-1119.

47. Alzeer M and MacKenzie KJD (2012) Synthesis and mechanical properties of new fibre-reinforced composites of inorganic polymers with natural wool fibres. Journal of Materials Science 47(19): 6958-6965.

48. Chapple S and Anandjiwala R (2010) Flammability of natural fiberreinforced composites and strategies for fire retardancy: a review. Journal of Thermoplastic Composite Materials 23(6): 871-893.

49. Echeverria CA, Handoko W, Pahlevani F and Sahajwalla V (2019) Cascading use of textile waste for the advancement of fibre reinforced composites for building applications. Journal of Cleaner Production 208: $1524-1536$.

50. Das O, Kim NK, Hedenqvist MS and Bhattacharyya D (2019) The flammability of biocomposites. In Durability and Life Prediction in Biocomposites, Fibre-reinforced Composites and Hybrid Composites (Jawaid M, Thariq M and Saba N (eds)). Woodhead Publishing, Duxford, UK, pp. 335-365.

51. Vieira MGA, Da Silva MA, Dos Santos LO and Beppu MM (2011) Natural-based plasticizers and biopolymer films: a review. European Polymer Journal 47(3): 254-263.

52. Ferri JM, Samper MD, García-Sanoguera D et al. (2016) Plasticizing effect of biobased epoxidized fatty acid esters on mechanical and thermal properties of poly(lactic acid). Journal of Materials Science 51(11): 5356-5366.

53. Charlet P, Leroy AM, Cattin-Vidal P and Le Mouton C (1953) Variation des caractéristiques des fibres de laine, selon les régions du corps chez le mouton plan du mémoire. Annales de Zootechnie, INRA/ EDP Sciences 2(2): 177-188 (in French).

54. Sánchez A (2016) Mejoras en el Proceso Industrial de Extracción de Lanolina del Efluente Procedente del Lavado de la Lana en Base a un Tratamiento Físico-Químico. Doctoral thesis, Universidad de Salamanca, Salamanca, Spain (in Spanish).

55. Makinson KR (1979) Shrinkproofing of Wool. Dekker, New York, NY, USA.

56. Margenat L, Torres Al, Moyna P et al. (2008) Lanoline purification by selective extraction of pesticides using supercritical $\mathrm{CO}_{2}$. Journal of Supercritical Fluids 45(2): 177-180.

57. Alzaga R, Pascual E, Erra P and Bayona JM (1999) Development of a novel supercritical fluid extraction procedure for lanolin extraction from raw wool. Analytica Chimica Acta 381(1): 39-48.

58. UNE (Spanish Association for Standardization) (2012) UNE-EN ISO 527-1:2012: Plastics - determination of tensile properties - part 1: general principles (ISO 527-1:2012). UNE, Madrid, Spain.

59. ISO (International Organization for Standardization) (2003) ISO 868:2003: Plastics and ebonite - determination of indentation hardness by means of a durometer (Shore hardness). ISO, Geneva, Switzerland.

60. ISO (2010) ISO 179-1:2010: Plastics - determination of Charpy impact properties - part 1: non-instrumented impact test. ISO, Geneva, Switzerland.

61. ISO (2010) ISO 178:2010: Plastics - determination of flexural properties. ISO, Geneva, Switzerland. 
62. Ferri JM, Garcia-Garcia D, Montanes N, Fenollar O and Balart R (2017) The effect of maleinized linseed oil as biobased plasticizer in poly(lactic acid)-based formulations. Polymer International 66(6): 882-891.

63. Conzatti L, Giunco F, Stagnaro P et al. (2014) Wool fibres functionalised with a silane-based coupling agent for reinforced polypropylene composites. Composites Part A: Applied Science and Manufacturing 61: 51-59.

64. Kelly FM and Johnston JH (2011) Colored and functional silver nanoparticle-wool fiber composites. ACS Applied Materials \& Interfaces 3(4): 1083-1092.

\section{How can you contribute?}

To discuss this paper, please submit up to 500 words to the journal office at journals@ice.org.uk. Your contribution will be forwarded to the author(s) for a reply and, if considered appropriate by the editor-in-chief, it will be published as a discussion in a future issue of the journal.

ICE Science journals rely entirely on contributions from the field of materials science and engineering. Information about how to submit your paper online is available at www.icevirtuallibrary.com/page/authors, where you will also find detailed author guidelines. 